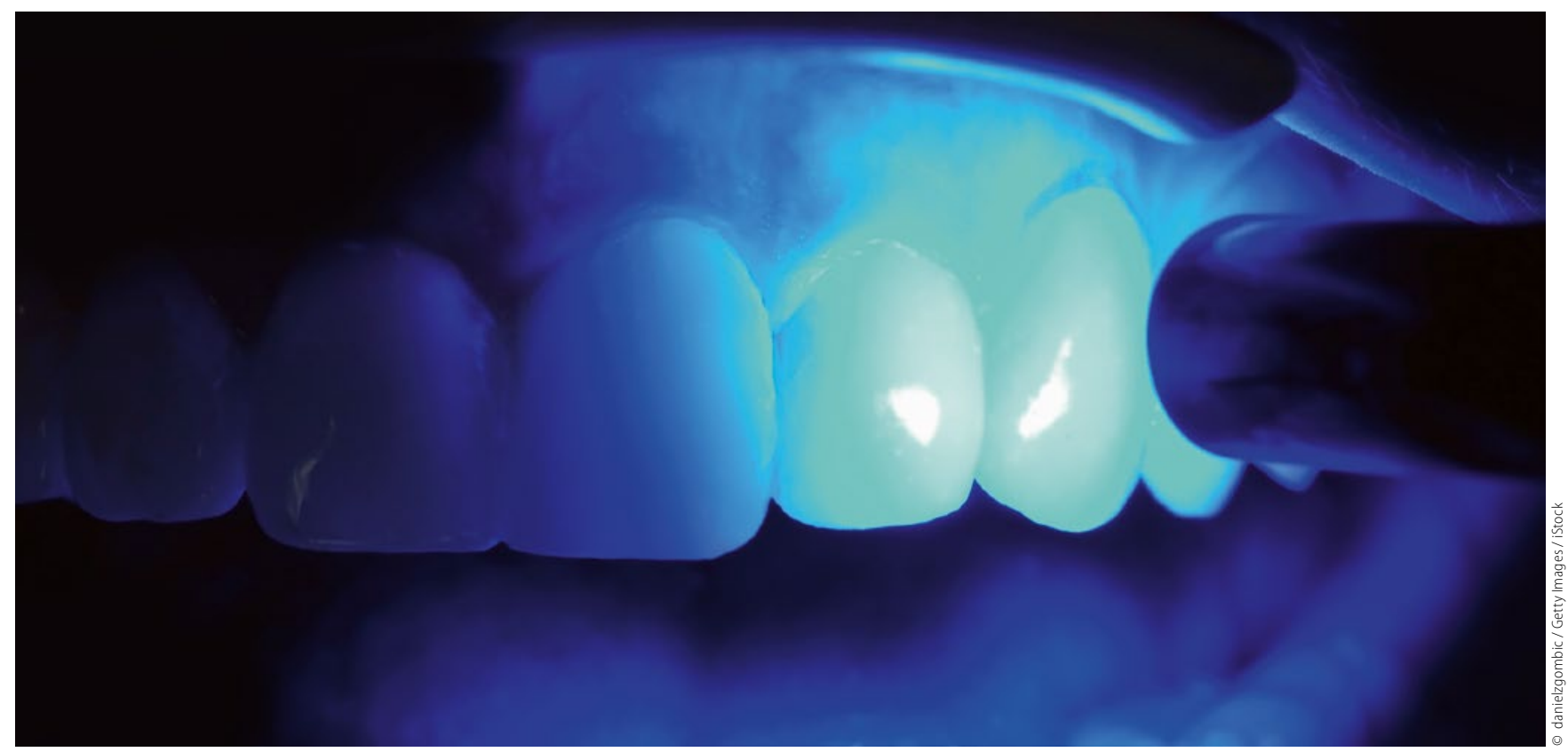

\title{
Laser zur Kariesbehandlung
}

\author{
Trotz vieler Fortschritte in der Zahnheilkunde ist die Zahnkaries eine weit verbreitete Erkran- \\ kung. Zur Therapie wird typischerweise mit rotierenden Instrumenten die erweichte Zahnhart- \\ substanz abgetragen. Die Kompositmaterialien mit ihrer adhäsiven Eigenschaft ermöglichen, die \\ Kavitäten mit Füllungen zu versehen, ohne Zahnhartsubstanz unnötig abzutragen. Als minimal- \\ invasive Methode, die Zahnkaries zu entfernen, kann heute der Laser genutzt werden, der die \\ Karies schmerzarm und geräuschlos entfernen soll.
}

Eine Metaanalyse der Cochrane-Datenbank (Montedori et al. 2016) untersuchte die bis heute veröffentlichten Arbeiten zu diesem Thema, indem sie randomisierte, kontrollierte Split-mouthStudien bei einer Literaturrecherche einschloss. Dabei wurde die Kariestherapie der Laserbehandlung mit der konventionellen Entfernung per Bohrer verglichen. Neun Studien aus den Jahren 1998 bis 2014 mit 662 Patienten und 1498 Zähnen wurden analysiert. Sowohl Milchzähne als auch bleibende Zähne waren mit verschiedenen Laserwellenlängen behandelt worden: Vier Studien nutzen einen Er:YAG, zwei Studien einen Er,Cr:YSGG und eine Studie einen Nd:YAG Laser.

Im Ergebnis klagten die konventionell behandelten Patienten häufiger über Schmerzen als die mit Laser behandelten Patienten. Auch der Verbrauch an Lokalanästhetikum war höher in der Gruppe konventioneller Kariesbehandlung. Die Haltbarkeit der anschließenden Restauration und das Wiederauftreten von Karies unterschieden sich nicht. Auch die Pulpa reagierte bei den in den USA, Taiwan, China, Bulgarien, Deutschland, Türkei und Großbritannien durchgeführten Studien nicht.

[Quelle: A. Montedori, I. Abraha, M. Orso, P.G. DÉrrico, S. Pagano, G. Lombargo (2016) Laser for caries removal in deciduous an dpermanent teeth (review). Cochrane Library]

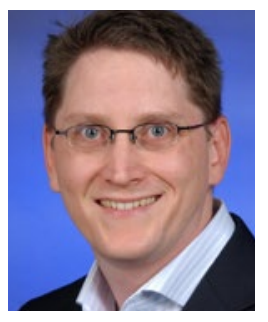

Prof. Dr. Dr. Felix P. Koch

Autor des Wissenschaftlichen Infodienstes, Lehrbeauftragter der Uniklinik Frankfurt, Praxisklinik für Mund-, Kiefer- und plastische Gesichtschirurgie in Wiesbaden. Mail:wid@fvdz.de 